\title{
Participatory ergonomic intervention for prevention of low back pain: assembly line redesign case
}

\author{
João Marcos Bernardes ${ }^{\mathrm{a},{ }^{*}}$, Claudia Wanderck ${ }^{\mathrm{b}}$ and Antônio Renato Pereira Moro ${ }^{\mathrm{c}}$ \\ ${ }^{a}$ Departamento de Engenharia de Produção e Sistemas, Universidade Federal de Santa Catarina, Campus \\ Universitário da Trindade, Trindade, Florianópolis, Santa Catarina, Brasil \\ ${ }^{\mathrm{b}}$ Long Life Fisioterapia, Rua Boaventura Amorim 16, Itoupava Norte, Blumenau, Santa Catarina, Brasil \\ ${ }^{\mathrm{c}}$ Departamento de Educação Física, Universidade Federal de Santa Catarina, Campus Universitário da \\ Trindade, Trindade, Florianópolis, Santa Catarina, Brasil
}

\begin{abstract}
This paper gives an overview of a participatory ergonomic intervention aimed at reducing low back pain cases in the dispatch department of a catalogue and e-commerce retail company. Based on the findings of the ergonomic analysis and design committee, the company's own employees redesigned the assembly line's layout. As a result of these changes two job tasks that involved manual material handling of boxes, identified by the revised NIOSH equation as posing an increased risk for lifting-related low back pain, were totally eliminated, and the employees responsible for moving boxes from the end of the assembly line to pallets on the ground were given more control over their jobs, and these jobs were also enriched with a new, less heavy task. These results demonstrate that participatory ergonomic interventions are a viable and effective strategy to reduce the exposure to work-related physical and psychosocial risk factors for low back pain.
\end{abstract}

Keywords: Work-related musculoskeletal disorders, low back pain, manual material handling, workplace interventions, participatory approach

\section{Introduction}

In spite of the extensive amount of information on the physiopathology, epidemiology and risk model of work-related musculoskeletal disorders (WMSD) accumulated in the last 20 years, they continue to be a major cause of lost time at work, lost productivity, workers' disability, compensation claims and health care costs, imposing a heavy burden on workers, workplaces and society at large [21,27,29]. In Brazil, according to data from the Social Welfare Ministry, WMSD represented $52.8 \%$ of all occupational diseases registered in $2001,55.3 \%$ in 2002 and $50.1 \%$ in 2003 [9].

Low back pain (LBP) represents one of the most common forms of WMSD, accounting for more than
$24 \%$ of all work-related musculoskeletal disorders $[7,35]$. Several factors that are important in LBP etiology are related with the workplace and as much as $30 \%$ of all LBP can be attributed to occupational exposures. The following physical occupational risk factors have been associated with the development of LBP: heavy physical work, bending and twisting, manual handling of objects or people and whole-body vibration [18,20,37].

In addition to the separate effects of each of these physical occupational risk factors, experimental evidence and biomechanical theory suggest that they may interact, producing a higher risk of LBP when combined. Biomechanical theory also predicts that local low-back muscle fatigue resulting from job-

\footnotetext{
* Adress for correspondence: Universidade Federal de Santa Catarina, Centro Tecnológico, Programa de Pós-Graduação em Engenharia de Produção, Campus Universitário, Trindade, Florianópolis, Santa Catarina, Brasil - CEP 88040-900. Tel. no. +55 (48) 9604-7362. E-mail: jmbernardes@yahoo.com.
} 
related physical effort may increase the risk of LBP associated with lifting [23,26,28,31,38].

Psychosocial factors at work have also been implicated in the development of LBP. Work-related psychosocial factors refer to the perceptions or beliefs that workers have about the way their work environment is organized $[11,19]$. Factors such as job dissatisfaction, monotony of work, limited job control, and lack of social support are the most commonly identified potential risk factors associated with the occurrence of LBP $[5,8,19]$.

In order to prevent occupational LBP, ergonomic interventions are frequently implemented at the workplace to reduce biomechanical and psychosocial load. However, the findings of a recent systematic review showed that the implementation of physical and organizational ergonomic interventions alone were not effective to prevent LBP [24]. It has been hypothesized that this lack of effects might be due to the inadequate implementation of ergonomic measures (i.e., compliance, satisfaction and experience) [6], therefore, the use of participatory ergonomics (PE), as a strategy to implement ergonomic measures, has been recommended by the National Institute of Occupational Safety and Health (NIOSH) and the European Agency for Safety and Health at Work (EASHW) as an important method for controlling WMSD and initiating an ergonomic program [4].

PE, an increasingly utilized method of improving ergonomic aspects of work and workplaces, consists in the workers' active involvement in the process to identify risk factors in the workplace, and to select the most appropriate solutions for these risks, supported by their supervisors and managers, in order to improve their working conditions $[16,17,22]$. PE has been claimed to add some advantages to the traditional ergonomic intervention, including enhanced intervention efficacy, added problem solving capability (essential for effective assessment of the multifactorial risks associated with WMSD), as well as better communication among workplace parties and better acceptance of change by the workforce (as a result of their increased ownership of workplace changes) $[3,13]$.

The participatory approach has already been used to reduce physical work demands and to prevent WMSD in several studies, presenting promising results $[2,13-15,30,33]$. Therefore, the purpose of this study was to present a participatory ergonomic intervention developed in the dispatch department of a Brazilian catalogue and e-commerce retail company, and its effectiveness in reducing exposure to work- related physical and psychosocial risk factors for LBP.

\section{Background}

The subject for this case study was a mid-sized (approximately 500 employees) catalogue and ecommerce retail company located in Blumenau, a 300,000 inhabitants town in the state of Santa $\mathrm{Ca}$ tarina, in the south region of Brazil.

In 2007 the company launched its official ecommerce website. Joining the e-commerce website market led the company to increase operations and shipping volume. However, along with the increase in operations and shipping, an increase in the frequency and severity of LBP cases occurred. Concerned about this increase in LBP cases and recognizing the need for improvements, management brought in ergonomists to help in finding the source of problems and possible solutions.

\section{Intervention process}

The intervention was based on group work: the employees and the ergonomists identified problems in the workplace and developed and evaluated solutions for them; while the changes were implemented involving the ergonomists, employees, management and technical personnel working together. The PE intervention included the following steps:

\subsection{Preparation}

In this step top management appointed management representatives for the steering committee, which was comprised of representatives from top management, human resources, health and safety department and an ergonomist. Following the steering committee formation, all employees of the department were informed of the project and encouraged to participate. The steering committee then directed the formation of the ergonomics analysis and design committee, which included production supervisors, production employees, maintenance personnel and an ergonomist.

\subsection{Workplace analysis}

This step was divided in three stages. In the first stage employees were interviewed to capture their 
responses to questions about musculoskeletal symptoms and the procedures, duration and the experienced heaviness of the tasks.

In the second stage the ergonomic analysis and design committee discussed a document which summarized the data obtained in the previous stage and had information on risk factors for LBP in the dispatch department, which had been indentified in a previous workplace analysis made by an ergonomist.

In the third stage, the employees could include other risk factors of LBP, and evaluated all mentioned risk factors according to their frequency and severity. Based on the committee's observation, the two most frequent and severe risk factors were prioritized for improvements.

During this step the employees were informally educated about basic ergonomics principles, risk analysis techniques, and workstation design guidelines.

\subsection{Solution building}

Subsequently, the ergonomic analysis and design committee held a brainstorming session, during which the committee's members were invited to propose, without restraint, different types of ergonomic interventions targeting the prioritized risk factors.

Then, a discussion was held between the steering committee and the ergonomic analysis and design committee regarding the advantages/disadvantages of each ergonomic intervention previously proposed, according to a criteria list considering: relative advantage, costs, compatibility and complexity. Based on a consensus, the most appropriate ergonomic measures were chosen.

\subsection{Solution implementation}

In this stage, the improvements were implemented into the actual workplace. To improve the implementation process, all employees were informed, motivated and instructed, in an informal way, about the ergonomic measures, in order to facilitate the acceptance of the changes made to the work process and the work area.

\subsection{Evaluation}

This step will take place after 6 and 12 month of the implementation of the improvements, when a questionnaire concerning musculoskeletal symptoms and sick leave data will be sent to the employees, providing information about the effectiveness of the intervention and indicating if adaptations or additional changes were necessary.

\section{Results}

\subsection{Results of step 2 - workplace analysis}

According to the workplace analysis, the two most frequent and severe risk factor for LBP in the dispatch department were related with configuration of the assembly line of the boxing and dispatch departments (Figure 1).

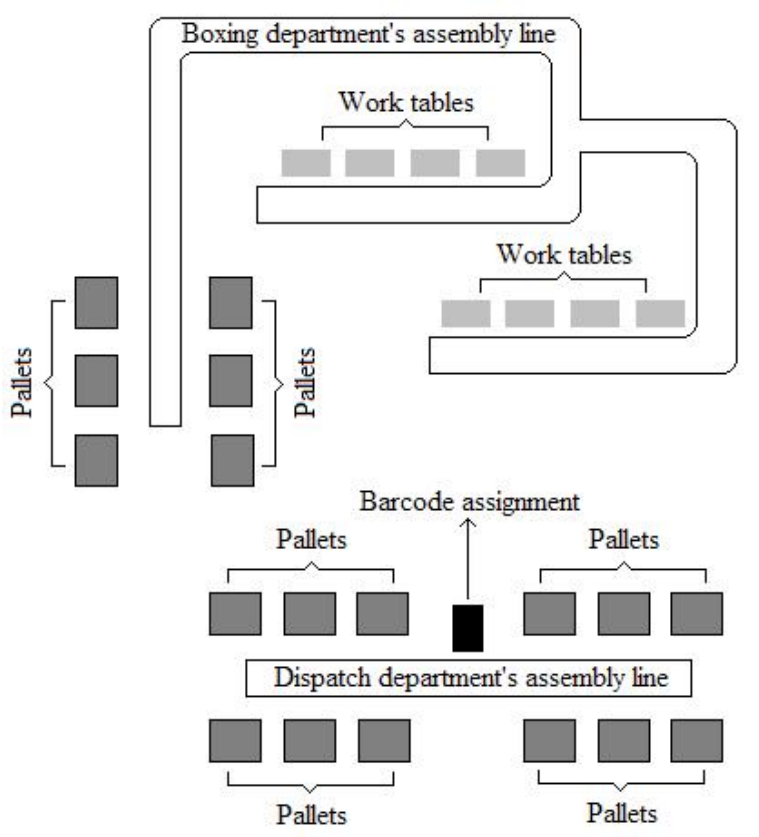

Fig. 1 - Boxing and dispatch departments' assembly line configuration before the intervention

As can be seen in Figure 1 both assembly lines were separated, therefore boxes coming from the boxing department had to be removed from the assembly line to pallets in the ground. Next, these pallets were moved to the dispatch department, where the boxes were put on the assembly line to receive their barcodes. Finally, the boxes were removed from the assembly line to pallets in the ground again. Consequently, these procedures required that employees handled the boxes three times, without any control over their work rhythm, since it was established by the assembly's line pace. 
Thus, repetitive manual material handling in awkward postures (excessive reaching, bending and twisting) was identified by the ergonomic analysis and design committee as the most frequent and severe risk factor for LBP in the dispatch department, followed by low job control.

\subsection{Results of step 3 - solution building}

Based on the results of the workplace analysis step, during the meeting where the ergonomic interventions were discussed by the steering committee and the ergonomic analysis and design committee, it was decided that the assembly line of the dispatch department was going to be combined with the assembly line of the boxing department and the assembly line's layout would be redesigned from a straight configuration to a circular arrangement (Figure 2).

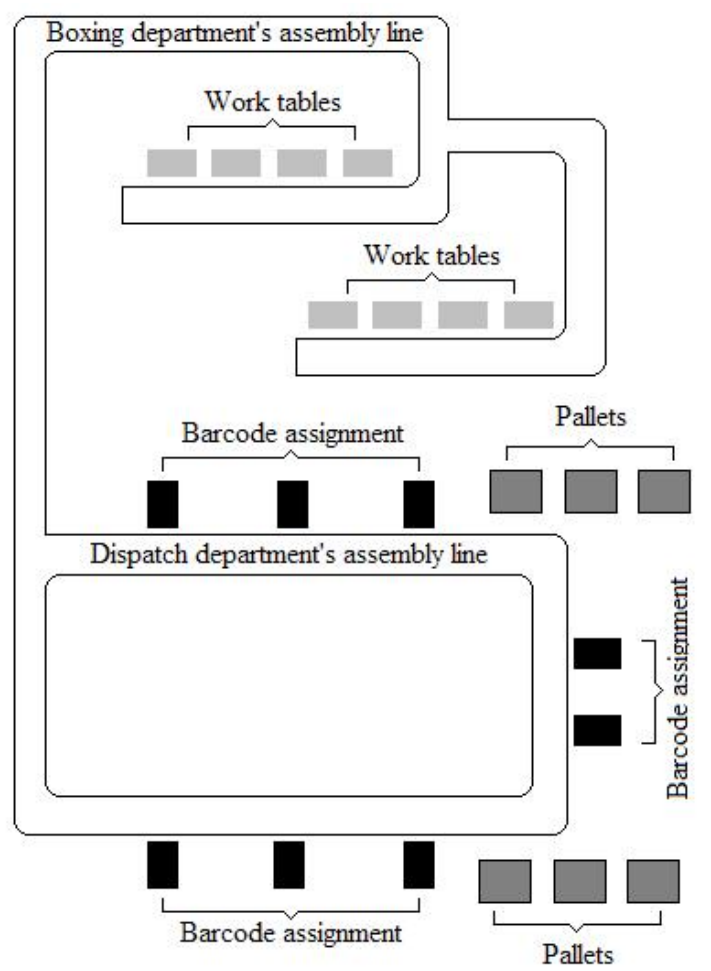

Fig. 2 - Boxing and dispatch departments' assembly line configuration after the intervention

This combination of the assembly lines eliminated manual material handling of boxes in the end of the boxing department's assembly line and in the beginning of the dispatch department's assembly line, two job tasks identified as posing an increased risk for lifting-related low back pain. The combination of both assembly lines also created an opportunity for the enrichment of the dispatch department's workers' job, since they were relocated from the eliminated manual material handling tasks to the barcode assignment task, after receiving training.

The redesign of the assembly line from a straight configuration to a circular arrangement gave to the employees responsible for moving boxes from the assembly line to pallets on the ground more control over their jobs, since the assembly line's new circular configuration allows missed boxes to be moved to the pallet later, reducing the influence of the boxing department's assembly line on the dispatch department's work rhythm.

\section{Discussion}

As a result of the combination of the dispatch department's assembly line with the assembly line of the previous department (responsible for boxing sold products), two job tasks that involved manual material handling of boxes, identified by the revised NIOSH equation [34] as posing an increased risk for lifting related low back pain (Lift index $>1.0$ ) were totally eliminated. Manual material handling involves considerable physical work demands and is considered to be high risk for the development or exacerbation of LBP symptoms; in fact numerous reviews have shown a relationship between manual material handling and musculoskeletal disorders in both industrial and health care settings [10].

The combination of both assembly lines not only eliminated two manual material handling tasks but also enriched the employees' jobs. It has been conjectured that work enrichment could provide both biomechanical diversity in work and the potential for muscular recuperation while securing long-term gains in organizational performance [36].

The redesign of the assembly line's layout, from a straight configuration to a circular arrangement, gave the employees responsible for moving boxes from the assembly line to pallets on the ground more control over their jobs. According to the work demandcontrol model [32], low control over one's job coupled with high demands, increases the likelihood of work-related health problems. In fact, in a longitudinal study of hospital workers [12], it was shown that low perceived job influence was an important predictor for musculoskeletal diseases; similarly, a longitudinal study of transit operators [25], showed that psychosocial factors were strong predictors of back and 
neck pain independent of physical risk factor predictors.

The results obtained in this case study show that the intervention process was effective in reducing physical and psychosocial risk factors for LBP. These findings support the conclusion of a systematic review that $\mathrm{PE}$ is effective for reducing workers' exposure to both physical and psychosocial risk factors [14]. Other studies, however, showed that that PE led to statistically significant reductions in mechanical exposures among automotive industry workers [2], but did not lead to statistically significant reductions in psychosocial workload [1].

\section{Conclusion}

The case study presented here extends the literature on efforts to reduce the burden of WMSD by demonstrating that a PE intervention can be a viable and effective strategy to reduce the exposure to workrelated physical and psychosocial risk factors for LBP. Moreover, this study strengthens the importance of employee participation in the whole process of change, since they know their workplace better than anyone else does and this knowledge allows them to develop a more thorough understanding of ergonomic problems and a more diagnostic approach to their solutions. As a result of the PE intervention, the assembly line of the dispatch department was combined with the assembly line of the previous department (responsible for boxing sold products) and the assembly line's layout was redesigned from a straight configuration to a circular arrangement. These changes eliminated two job tasks that involved manual material handling of boxes, identified by the revised NIOSH equation as posing an increased risk for lifting related low back pain (Lift index $>1.0$ ) and gave to the employees responsible for moving boxes from the end of the assembly line to pallets on the ground more control over their jobs, which were also enriched with a new, less heavy task. It is expected that these improvements decrease the number of LBP complaints and sick leave because of back pain. The measurement of LBP incidence and sick leave in the dispatch department, after 6 and 12 month intervention period, is a priority for future research.

\section{References}

[1] A.C. Laing, D.C. Cole, N. Theberge, R.P. Wells, M.S. Kerr and M.B. Frazer, Effectiveness of a participatory ergonomics intervention in improving communication and psychosocial exposures, Ergonomics 50 (2007), 1092-1109.

[2] A.C. Laing, M.B. Frazer, D.C. Cole, M.S. Kerr, R.P. Wells and R.W. Norman, Study of the effectiveness of a participatory ergonomics intervention in reducing worker pain severity through physical exposure pathways, Ergonomics 48 (2005), $150-170$.

[3] A.S. Imada, The rationale and tools of participatory ergonomics, in: Participatory ergonomics, K. Noro and A.S. Imada, eds, Taylor and Francis, London, 1991, pp. 30-50.

[4] D.M. Zalk, Grassroots ergonomics: initiating an ergonomics program utilizing participatory technique, Annals of Occupational Hygiene 45 (2001), 283-289.

[5] E. Clays, D. De Bacquer, F. Leynen, M. Kornitzer, E. Kittel and G. De Backer, The impact of psychosocial factors on low back pain: longitudinal results from the Belstress study, Spine 32 (2007), 262-268.

[6] E. Haukka, P. Leino-Arjas, E. Viikari-Juntura, E.P. Takala, A. Malmivaara, L. Hopsu, P. Mutanen, R. Ketola, T. Virtanen, I. Pehkonen, M. Holtari-Leino, J. Nykänen, S. Stenholm, E. Nykyri and H. Riihimäki, A randomised controlled trial on whether a participatory ergonomics intervention could prevent musculoskeletal disorders, Occupational and Environmental Medicine 65 (2008), 849-856.

[7] E. Johanning, Evaluation and management of occupational low back disorders, American Journal of Industrial Medicine 37 (2000), 94-111.

[8] G.J. Macfarlane, N. Pallewatte, P. Paudyal, F.M. Blyth, D. Coggon, G. Crombez, S. Linton, P. Leino-Arjas, A.J. Silman, R.J. Smeets and D. van der Windt, Evaluation of work-related psychosocial factors and regional musculoskeletal pain: results from a EULAR Task Force, Annals of the Rheumatic Diseases 68 (2009), 885-891.

[9] G. Mussi and N. Gouveia, Prevalence of work-related musculoskeletal disorders in Brazilian hairdressers, Occupational Medicine 58 (2008), 367-369.

[10]H.F. van der Molen, J.K. Sluiter, C.T.J. Hulshof, P. Vink and M.H.W Frings-Dresen, Effectiveness of measures and implementation strategies in reducing physical work demands due to manual handling at work, Scandinavian Journal of Work, Environment and Health 31 (2005), 75-87.

[11]H. Lee, J. Wilbur, M.J. Kim and A.M. Miller, Psychosocial risk factors for work-related musculoskeletal disorders of the lower-back among long-haul international female flight attendants, Journal of Advanced Nursing 61 (2008), 492-502.

[12]H.S. Shannon, C.A. Woodward, C.E. Cunningham, J. McIntosh, B. Lendrum, J. Brown and D. Rosenbloom, Changes in general health and musculoskeletal outcomes in the workforce of a hospital undergoing rapid change: a longitudinal study, Journal of Occupational Health Psychology 6 (2001), 3-14.

[13]I. Rivilis, D.C. Cole, M.B. Frazer, M.S. Kerr, R.P. Wells and S Ibrahim, Evaluation of a participatory ergonomic intervention aimed at improving musculoskeletal health, American Journal of Industrial Medicine 49 (2006), 801-810.

[14]I. Rivilis, D. Van Eerd, K. Cullen, D.C. Cole, E. Irvin, J. Tyson and Q. Mahood, Effectiveness of participatory ergonomic interventions on health outcomes: a systematic review, Applied Ergonomics 39 (2008), 342-358.

[15]J.C. Rosecrance and T.M. Cook, The use of participatory action research and ergonomics in the prevention of workrelated musculoskeletal disorders in the newspaper industry, Applied Occupational and Environmental Hygiene 15 (2000), 255-262.

[16]J.R. Anema, I.A. Steenstra, I.J. Urlings, P.M. Bongers, E.M. de Vroome and W. van Mechelen, Participatory ergonomics as 
a return-to-work intervention: a future challenge?, American Journal of Industrial Ergonomics 44 (2003), 273-281.

[17]K. Kogi, Participatory methods effective for ergonomic workplace improvement, Applied Ergonomics 37 (2006), 547-554.

[18] L. Punnett, A. Prüss-Utün, D.I. Nelson, M.A. Fingerhut, J. Leigh, S. Tak and S. Phillips, Estimating the global burden of low back pain attributable to combined occupational exposures, American Journal of Industrial Medicine 48 (2005), 459-469.

[19] M. Ghaffari, A. Alipour, A.A. Farshad, I. Jensen, M. Josephson and E. Vingard, Effect of psychosocial factors on low back pain in industrial workers, Occupational Medicine 58 (2008), 341-347.

[20] M. Krismer and M. van Tulder, Low back pain (non-specific), Best Practice \& Research Clinical Rheumatology 21 (2007), 77-91.

[21]M.L. Baldwin, Reducing the costs of work-related musculoskeletal disorders: targeting strategies to chronic disability cases, Journal of Electromyography and Kinesiology 14 (2004), 33-41.

[22] M. Nagamachi. Requisites and practices of participatory ergonomics, International Journal of Industrial Ergonomics 15 (1995), 371-377.

[23] M. Parnianpour, M. Nordin, N. Kahanovitz and V. Frankel, 1988 Volvo award in biomechanics. The triaxial coupling of torque generation of trunk muscles during isometric exertions and the effect of fatiguing isoinertial movements on the motor output and movement patterns, Spine 13 (1998), 982-992.

[24] M.T. Driessen, K.I. Proper, M.W. van Tulder, J.R. Anema, P.M. Bongers and A.J. van der Beek, The effectiveness of physical and organisational ergonomic interventions on low back pain and neck pain: a systematic review, Occupational and Environmental Medicine 67 (2010), 277-285.

[25]N. Krause, D.R. Ragland, B.A. Greiner, S.L. Syme and J.M. Fisher, Psychosocial job factors associated with back and neck pain in public transit operators. Scandinavian Journal of Work, Environment and Health 23 (1997), 179-186.

[26] O.O. Okunribido, M. Magnusson and M.H. Pope, The role of whole body vibration, posture and manual material handling as risk factors for low back pain in occupational drivers, Ergonomics 51 (2008), 308-329.

[27]P. Buckle, Ergonomics and musculoskeletal disorders: overview, Occupational Medicine 55 (2005), 164-167.

[28]P. Dolan and M.A. Adams, Repetitive lifting tasks fatigue the back muscles and increase the bending moment acting on the lumbar spine, Journal of Biomechanics 31 (1998), 713-721.

[29]P. Jezukaitis and D. Kapur, Management of occupation-related musculoskeletal disorders, Best Practice \& Research Clinical Rheumatology 25 (2011), 117-129.

[30]P. Vink, E.A. Koningsveld and J.F. Molenbroek JF, Positive outcomes of participatory ergonomics in terms of greater comfort and higher productivity, Applied Ergonomics 37 (2006), 537-546.

[31] R.G. Radwin, W.S. Marras and S.L. Lavender, Biomechanical aspects of work-related musculoskeletal disorders, Theoretical Issues in Ergonomics Science 2 (2001), 153-217.

[32] R. Karasek and T. Theorell, Healthy work, stress, productivity and the reconstruction of working life. Basic Books, New York, 1990.

[33] S. Hignett, J.R. Wilson and W. Morris, Finding ergonomic solutions - participatory approaches, Occupational Medicine 55 (2005), 200-207.

[34] T.R. Waters, V. Putz-Anderson, A. Garg and L.J. Fine, Revised NIOSH equation for the design and evaluation of manual lifting tasks, Ergonomics 36 (1993), 749-776.
[35]U.S. Bureau of Labor Statistics, Lost-worktime injuries and illnesses: Characteristics and resulting time away from work, 2000, USDL Number 02-196, Washington D.C. (2002).

[36] W.P. Neumann and L. Medbo, Ergonomic and technical aspects in the redesign of material supply systems: Big boxes vs. narrow bins, International Journal of Industrial Ergonomics 40 (2010), 541-548.

[37] W.S. Marras, Occupational low back disorder causation and control, Ergonomics 43 (2000), 880-902.

[38] W.S. Marras, S.A. Lavender, S.E. Leurgans, F.A. Fathallah, S.A. Ferguson, W.G. Allread and S.L. Rajulu, Biomechanical risk factors for occupationally related low back disorders, Ergonomics 38 (1995), 377-410. 